\title{
Conxuntura laboral do mes de marzo de 2020 nas princi- pais ramas de actividade cul- tural. Datos de afiliación á Seguridade Social
}

A declaración do estado de alarma por parte das autoridades dispón, entre outras cousas, a suspensión de apertura ao público de locais de actividade comercial, así como de equipamentos culturais. As actividades ás que se refire atópanse recollidas nos diferentes decretos promulgados e son, entre outras, as relativas a museos, arquivos, bibliotecas, monumentos, espectáculos públicos, auditorios, cines, salas de concertos, salas de
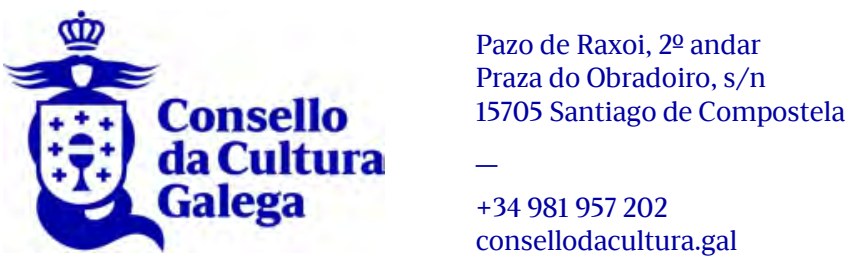
conferencias e de exposicións, teatros, aos que habería que engadir os recintos de hostalaría onde se realizan espectáculos de artes escénicas e musicais en directo.

Como se sabe, segundo a Conta Satélite da Cultura (CSC), a cultura representa en Galicia o 2\% do PIB e o 3\% do emprego. Nun mes medio ${ }^{1}$, recádanse 1,9 millóns de euros de 325.000 asistentes nas salas de cine galegas. Hai 140 representacións de artes escénicas e unha media de 40.000 espectadores, que supoñen unha recadación de $350.000 €$. En canto á música en vivo, teñen lugar uns 400 concertos por mes, que congregan 145.000 espectadores e xeran unha recadación media mensual de case 1,5 millóns de euros. A poboación galega gasta aproximadamente nese mesmo mes medio en total uns 52 millóns de euros en cultura, dos cales 6,7 millóns se destinan a espectáculos e outros servizos culturais. Do total do turismo cultural que recibe Galicia, só os turistas que proveñen do resto de España realizan un gasto de 15,5 millóns de euros de media mensual.

DOCUMENTOS DE TRABALLO

Por sectores da cultura, tal e como se recolle na CSC, o que máis achega á produción é o chamado de artes visuais, que inclúe actividades de deseño, fotografía, creación artística e de fabricación e comercio de bens relacionados con elas así como algunhas fases da arquitectura e da publicidade; o segundo en importancia é o sector do libro e da prensa e en terceiro lugar atópase o audiovisual e o multimedia (radio, televisión, cine, vídeo e música gravada); o cuarto é o sector das actividades de explotación do patrimonio artístico e monumental, arquivos e bibliotecas; o quinto compóñeno as artes escénicas (teatro, ópera, concertos musicais e outros moitos tipos de espectáculos escénicos en vivo).

Por fases da cadea de produción, a que achega maior valor engadido no eido da cultura é a de creación e produción, que supón un 70,6\% do valor engadido bruto (VEB). En termos de emprego, tamén é esta fase a que proporciona a maior porcentaxe de emprego, concretamente o $64,7 \%$ dos postos de traballo. A seguinte actividade que achega maior VEB, pero xa moi lonxe da primeira, é a de distribución e comercialización, concretamente un $12,6 \%$, e a de fabricación, cun 10,9\%.

Como xa se mencionou en informes anteriores ${ }^{2}$, a estrutura do emprego nas actividades culturais indica que, en comparación coa totalidade do tecido empresarial, hai maior dependencia das empresas máis pequenas e

\footnotetext{
${ }^{1}$ Media calculada a partir do último ano de referencia de cada estatística.

${ }^{2}$ http://consellodacultura.gal/publicacion.php?id=4348
} 
DOCUMENTOS DE TRABALLO

DOCUMENTOS DE TRABALLO

menos concentración nas grandes. De feito, o Observatorio da Cultura Galega puxo de manifesto que "no tocante ao estrato de asalariados das empresas culturais en Galicia, obsérvase que máis da metade non tiña ningún asalariado, xa que son actividades de autoemprego. 0 99,5\% son pemes"3. Ademais, o emprego cultural experimenta unha importante estacionalidade, maior que a do total do emprego. O número de autónomos nas actividades culturais supera en proporción ao total de actividades. Concretamente, en febreiro de 2020, case o 30,8\% dos empregados da cultura eran autónomos. Nas actividades de creación, artísticas e de espectáculos esta proporción era do $64,1 \%$.

O enfoque que se fai da cadea de produción na CSC permite entender con facilidade como afecta o peche de actividades ao conxunto da cultura. No caso do sector do libro, por exemplo, o peche na práctica de comercios de venda de libros afecta ao conxunto da produción, dado que as editoras non poden poñer no mercado das librarías con local comercial as súas novidades. Por outra banda, pese a que non se decreta o cesamento de todo o sector cultural, as restricións ao movemento de persoas, así como as medidas relativas ao mantemento de distancias de seguridade, impiden a realización de actividades como rodaxes de cine e televisión, ensaios teatrais e musicais etc. Así mesmo, algunhas actividades de fabricación son moi difíciles de levar a cabo para cumprir coas medidas de prevención e, ademais, moitas actividades da cultura son inviables de realizar a distancia.

Algunhas actividades, que aparentemente non deberan verse demasiado afectadas, como aquelas de natureza eminentemente creativa, poden ter tamén dificultades, porque se realizan tamén actividades de difusión e comercialización dos bens e servizos que producen, posto que moitas son empresas moi pequenas nas que se leva a cabo case a totalidade das fases en que se atopa o produto ou servizo que ofrecen.

Outras actividades como as relativas á radiodifusión e á emisión de televisión seguen activas, pero vense afectadas por problemas relacionados coa cadea de produción e coas restricións de movemento e distancia entre as persoas, que dificultan de forma importante a organización da actividade.

Nesta conxuntura recóllense os datos das afiliacións á Seguridade Social a partir da explotación que ofrece o Instituto Galego de Estatística (IGE)

\footnotetext{
${ }^{3}$ http://consellodacultura.gal/mediateca/extras/CCG 2016 O-sistema-produtivo-dacultura-2016.pdf
} 
dos datos do Ministerio de Trabajo y Economía Social das e dos traballadores adscritos a actividades culturais. Isto significa que só se recollen datos das persoas empregadas nas principais empresas culturais, pero non das persoas con ocupacións culturais que dependen doutro tipo de actividades, nin dos que traballan en ramas de actividades que non son distinguibles polo nivel de desagregación que ofrece a estatística. $\mathrm{O}$ Observatorio da Cultura Galega fará unha revisión periódica dos principais indicadores estatísticos nos vindeiros meses.

A fonte explotada para a elaboración deste informe provén da seguinte estatística: Instituto Galego de Estatística. Afiliacións á Seguridade Social por ramas de CNAE 2009. Ministerio de Trabajo y Economía Social.

\section{Resultados}

As afiliacións á Seguridade Social das principais industrias culturais de Galicia baixaron un 5,5\% no mes de marzo, o cal significa 868 cotizantes menos, polo que o total queda en 15.013. As variacións porcentuais por ramas de actividades son as que seguen:

Afiliacións á Seguridade Social no último día do mes nas principais industrias culturais por ramas de actividade en Galicia

\begin{tabular}{|c|c|c|c|}
\hline & Febreiro & Marzo & $\begin{array}{r}\text { Varia- } \\
\text { ción }\end{array}$ \\
\hline $\begin{array}{l}18 \text { Artes gráficas e reprodución de soportes grava- } \\
\text { dos }\end{array}$ & 3.320 & 3.240 & $-2,4 \%$ \\
\hline 58 Edición & 2.207 & 2.174 & $-1,5 \%$ \\
\hline $\begin{array}{l}59 \text { Actividades cinematográficas, de vídeo e de } \\
\text { programas de televisión, gravación de son e edi- } \\
\text { ción musical }\end{array}$ & 1.439 & 1.221 & $-15,1 \%$ \\
\hline $\begin{array}{l}60 \text { Actividades de programación e emisión de ra- } \\
\text { dio e televisión }\end{array}$ & 1.398 & 1.372 & $-1,9 \%$ \\
\hline 63 Servizos de información & 933 & 897 & $-3,9 \%$ \\
\hline 73 Publicidade e estudos de mercado & 3.587 & 3.355 & $-6,5 \%$ \\
\hline 90 Actividades de creación, artísticas e espectácu- & 2.516 & 2.291 & $-8,9 \%$ \\
\hline $\begin{array}{l}91 \text { Actividades de bibliotecas, arquivos, museos e } \\
\text { outras actividades culturais }\end{array}$ & 481 & 463 & $-3,7 \%$ \\
\hline Total & 15.881 & 15.013 & $-5,5 \%$ \\
\hline
\end{tabular}

Tal como se pode comprobar, as ramas de actividade máis afectadas son as cinematográficas, de vídeo e de programas de televisión, gravación de 
son e edición musical, seguidas das actividades de creación, artísticas e espectáculos.

As afiliacións descenderon con menos forza que no conxunto do Estado, onde a caída foi de 27.874 traballadores, o que supón un descenso do $6,5 \%$. As ramas máis castigadas foron as mesmas que en Galicia.

Por réximes, temos estes datos:

\begin{tabular}{|c|c|c|}
\hline & R. xeral & $\begin{array}{r}\text { R. especial de } \\
\text { autónomos }\end{array}$ \\
\hline 18 Artes gráficas e reprodución de soportes gravados & $-2,9 \%$ & $-1,0 \%$ \\
\hline 58 Edición & $-1,7 \%$ & $-0,3 \%$ \\
\hline $\begin{array}{l}59 \text { Actividades cinematográficas, de vídeo e de pro- } \\
\text { gramas de televisión, gravación de son e edición }\end{array}$ & & \\
\hline $\begin{array}{l}\text { musical } \\
60 \text { Actividades de programación e emisión de radio }\end{array}$ & $-21,6 \%$ & $0,2 \%$ \\
\hline e televisión & $-1,9 \%$ & $0,0 \%$ \\
\hline 63 Servizos de información & $-5,4 \%$ & $-0,7 \%$ \\
\hline 73 Publicidade e estudos de mercado & $-9,5 \%$ & $-0,6 \%$ \\
\hline 90 Actividades de creación, artísticas e espectáculos & $-23,0 \%$ & $-1,1 \%$ \\
\hline $\begin{array}{l}91 \text { Actividades de bibliotecas, arquivos, museos e } \\
\text { outras actividades culturais }\end{array}$ & $-4,0 \%$ & $-1,8 \%$ \\
\hline Total & $-7,6 \%$ & $-0,7 \%$ \\
\hline
\end{tabular}

Fonte: Explotación do Instituto Galego de Estatística de información subministrada directamente polo Ministerio de Trabajo, Migraciones y Seguridad Social

O descenso foi maior entre os afiliados no réxime xeral $(-7,6 \% \%)$ que entre os de autónomos (-0,7\%). Esta diferenza podería deberse á posibilidade de acceder á prestación extraordinaria por cesamento de actividade dos autónomos, que implica que, durante o período de percepción da prestación, o traballador que suspende a actividade continúa de alta no réxime de autónomos.

A táboa de variacións dos totais da cultura por provincias indica que a maior perda de traballo se produciu proporcionalmente nas provincias da Coruña e Ourense. 


\section{Variacións das afiliacións á Seguridade Social entre o último día do mes de marzo e de febreiro de $\mathbf{2 0 2 0}$ nas principais industrias cultu- rais por provincias}

\begin{tabular}{lc} 
Provincias & Febreiro 2020 \\
\hline A Coruña & $-5,9 \%$ \\
Lugo & $-2,6 \%$ \\
Ourense & $-5,9 \%$ \\
Pontevedra & $-5,1 \%$ \\
\hline
\end{tabular}

Fonte: Explotación do Instituto Galego de Estatística de información subministrada directamente polo Ministerio de Trabajo, Migraciones y Seguridad Social

Se se compara a cultura cos grandes sectores da economía e co total de afiliacións, obtéñense os seguintes resultados:

Variacións das afiliacións á Seguridade Social do último día do mes de marzo e de febreiro de 2020 por sectores

\begin{tabular}{lr} 
Sectores & Variación marzo/feb. 2020 \\
\hline Agricultura e pesca & $-0,6 \%$ \\
Industria & $-2,1 \%$ \\
Construción & $-5,6 \%$ \\
Servizos & $-3,4 \%$ \\
Cultura & $-5,5 \%$ \\
Total & $-3,2 \%$ \\
\hline
\end{tabular}

Fonte: IGE. Afiliacións á Seguridade Social por ramas de CNAE 2009

A variación por sectores indica que a cultura experimentou descensos maiores ca o resto dos sectores agás a construción. Comparado co total de actividades, a cultura perdeu 2,3 puntos porcentuais máis que o total.

A continuación ofrécense os datos das ramas de actividade con maiores descensos nas afiliacións.

Variacións das afiliacións á Seguridade Social do último día do mes de marzo e de febreiro de 2020 nas 15 ramas con maiores descensos

Variación marzo/feb.

Ramas de actividade 2020

78 Actividades relacionadas co emprego $-49,5 \%$

39 Actividades de descontaminación e outros servizos de xestión de residuos

59 Actividades cinematográficas, de vídeo e de programas de tele-

visión, gravación de son e edición musical

50 Transporte marítimo e por vías navegables interiores 
93 Actividades deportivas, recreativas e de entretemento $\quad-8,7 \%$

55 Servizos de aloxamento $\quad-8,5 \%$

77 Actividades de alugueiro $\quad-7,4 \%$

06 Extracción de cru de petróleo e gas natural $\quad-6,7 \%$

79 Actividades de axencias de viaxes, operadores turísticos, servi-
zos de reservas e actividades relacionadas con estes

82 Actividades administrativas de oficina e outras actividades auxi-

liares das empresas $\quad-6,6 \%$

73 Publicidade e estudos de mercado $\quad-6,5 \%$

74 Outras actividades profesionais, científicas técnicas $\quad-6,2 \%$

Fonte: IGE. Afiliacións á Seguridade Social por ramas de CNAE 2009

Tal e como se pode comprobar, das 15 ramas de actividade máis afectadas, tres correspóndese co sector cultural. Á marxe da rama 78, que rec olle a actividade das empresas de traballo temporal, e a 39, que comprende moi poucos casos, as actividades cinematográficas, de vídeo e de programas de televisión, gravación de son e edición musical e as actividades de creación, artísticas e espectáculos atópanse entre as máis afectadas.

\section{Conclusións}

Nesta breve conxuntura lémbrase, a partir de datos coñecidos e previos á crise provocada pola COVID-19, a relevancia do sector cultural en termos económicos e de emprego, que pode resumirse en que a cultura xera o 2\% do PIB galego e o 3\% do traballo. Tamén se lembran debilidades coñecidas do sector, como a temporalidade, o pequeno tamaño das empresas culturais e a alta incidencia de traballadores autónomos. Así mesmo, descríbese o funcionamento da cadea de produción da cultura e as súas fases e como afectan a unhas e outras as medidas decretadas polo Goberno para facer fronte á emerxencia sanitaria.

Como era de esperar, a situación de crise afectou ao emprego cultural, tal como se pode comprobar nos datos de afiliación do último día de mes de marzo de 2020, comparado co mes anterior. A cultura descendeu un 5,5\%, 2,3 puntos porcentuais máis que o conxunto do mercado laboral.

As ramas de actividade máis afectadas son as cinematográficas, de vídeo e de programas de televisión, gravación de son e edición musical, seguidas das actividades de creación, artísticas e espectáculos, que, de feito, se atopan entre as máis afectadas de todas as ramas que compoñen a economía galega. 
Por réximes de actividade, vense moito máis afectados os traballadores do réxime xeral que o de autónomos, posiblemente pola posibilidade de acceder á prestación extraordinaria por cesamento de actividade destes últimos.

Por provincias, as que perderon máis cotizantes en proporción foron A Coruña e Ourense.

Comparado con outros sectores, o da cultura perdeu proporcionalmente máis cotizacións que o conxunto dos servizos, a industria e o sector primario. Só é equiparable o descenso ao producido na construción.

En comparación co total do sector cultural de España, o descenso foi un pouco menor en Galicia, cunha diferenza dun punto porcentual. 